\title{
Development of a framework for the valuation of Eco- System Services of Green Infrastructure
}

\author{
Jayasooriya V.M a and A.W.M. Ng ${ }^{\text {a }}$ \\ ${ }^{a}$ Collage of Engineering and Science, Victoria University, Melbourne, Australia, 14428, AUSTRALIA \\ Email: varuni.jayasooriya@live.vu.edu.au
}

\begin{abstract}
With the rapid urban growth and development, the quality of green space available is consequently been degrading. Furthermore, many land characteristics have been altered such that the whole water cycle has been significantly changed. Some of the considerable adverse effects occur by these changes include the increase of runoff which can lead to flooding and the poor quality of receiving waters. Therefore, to improve the quality of the prevailing surface conditions whilst managing the stormwater, Green Infrastructure (GI) have been introduced which is becoming one of the promising practices of restoring the natural environment across many countries around the world. The term GI in the literature is commonly referred as Low Impact Development (LID), Best Management Practices (BMP), Sustainable Urban Drainage Systems (SUSD), Water Sensitive Urban Design (WSUD) and Low Impact Urban Design and Development (LIUDD) in different contexts (Eliot and Trowsdale, 2006). GI in broader terms can be defined as an "interconnected network of green space that conserves natural systems and provides assorted benefits to human populations" (McMahon and Benedict, 2006). GI can be grouped into two main categories structural and non-structural. The former include green roofs, rainwater tanks, wetlands, bio swales, pervious pavement, stormwater detention systems, planter boxes, cisterns, rain barrels and downspout disconnection amongst others. Nonstructural GI is designing the buildings or roads to minimize the imperviousness, improvement of the infiltration ability of soils by amending the properties and improving the vegetation of specific site or region. (Eliot and Trowsdale, 2006)
\end{abstract}

Though GI is best known as an alternative to conventional stormwater management strategies, it has been proven that apart from managing stormwater GI can provide a wide range of benefits known as Eco-system Services (ESS) (CNT, 2009). Such benefits include reducing Urban Heat Island (UHI), improving air quality, saving the energy, climate change and adaptation, improving habitats and community livability amongst others. Currently, different countries across the world are committing investments on promoting the benefits of having GI within their communities and therefore it is very important to have a comprehensive study on the value of the ESS they can provide. Such holistic assessment will demonstrate to stakeholders as well as the general public that the application of GIs not only a stormwater management strategy but have many social and environmental benefits. Furthermore, when these benefits can be transferred into monetary value then wider community will appreciate the importance of GI implementation in their society.ESS of GI in six main initial categories. They are water, energy, air, UHI, climate change and community liveability.

The ESS of GI can be studied in terms of environmental, economic and social benefits. Since the representation of benefit of each of the ESS in monetary terms can concentrate the results in to a final common resource unit, the economic benefits of these practices can produce are used for the cumulative valuation in the framework development. The valuation is done by using formulas adopted by different researchers in previous studies and applied for the conditions in Melbourne Australia. Melbourne is the second largest city in Australia with a highest rate of urban growth. Due to this scenario the green space available within the area is alarmingly degraded by creating the importance among professionals and government bodies in developing new ways to improve the region's natural environment. Therefore, the aim of this project is to develop a framework for valuing ESS of GI for Melbourne, Australia. The framework is then applied to a hypothetical case study with a green roof area of 300 square meters considering rainfall, temperature, and pricing for utilities in Melbourne area. The results of the ESS assessment indicates that a green roof located in Melbourne can approximately reduce 93 kiloliters of rainfall runoff per year and provide an economic benefit of 1245 AUD per annum by considering its energy, air quality and climate change benefits.

Keywords: Green Infrastructure (GI), Eco-system Services (ESS), benefit valuation 
Jayasooriya and Ng, Development of a framework for the valuation of Eco-System Services of Green Infrastructure

\section{INTRODUCTION}

Urban sprawl and infrastructure development have been made enormous pressures on the available green space in an urban unit of a country. The reduction of pervious surfaces associated with green space creates numerous adverse impacts on the natural water resources by creating high velocity flows of stormwater during peak flows, polluted with contaminants, sediments, oil, fertilizer, heavy metals and pathogens which directly transports through the pipelines to the receiving water bodies. These peak flows can erode steam banks, natural channels, and deposit pollutants that pose eco-system and public health risks. (McMullan and Reich, 2007) Green Infrastructure (GI) practices provide the measures to avoid or minimize environmental impacts of urbanization in terms of the demand for water and the potential pollution threat to natural water ways.

Recent research studies have identified that implementation of GI practices not only a stormwater management strategy that improves both water quantity and quality within the water cycle, but can also provide other important Eco-system Services (ESS). Such ESS can be classified into six main groups. These are water, energy, air quality, climate change, urban heat effect (UHE), and community livability, which include aesthetics, recreation, reduced noise pollution and community cohesion (Tzoulas et al., 2007). Chicago in the US is the leader in promoting green roofs in city buildings as part of their strategy to combat the combined stormwater overflow problems. To date, Chicago has over 400 green roofs implemented across the buildings which has decrease stormwater runoff and improve air quality. Furthermore, it has been reported that \$US 5000 of energy costs have been saved due to reduction in UHE with air temperature reduction of 15 degrees in the city and roof surface temperature reduction of 70 degrees (ASLA, 2003). Another study in Philadelphia, US where they have evaluated that if a combination of GI practices were to be implemented across their city, 196 premature fatalities can be avoided during extreme heat events (McPherson, 2006).

\subsection{Significance of the research}

The application of GI practices is becoming popular in many parts of the world. However, to quantify ESS in monetary terms still pose a challenge due to the lack of research studies in evaluation methods and the variations of benefits within different geographical scales. Previous approaches (Mcmullan and Reich 2007, Wise et al., 2010) were taken to quantify the ESS in different contexts and the values can be changed extensively due to site or region specific parameters such as climatic and atmospheric conditions which cannot be directly applied within the regions of Australia. And none of these studies does include a valuation of ESS that a specific GI can provide.

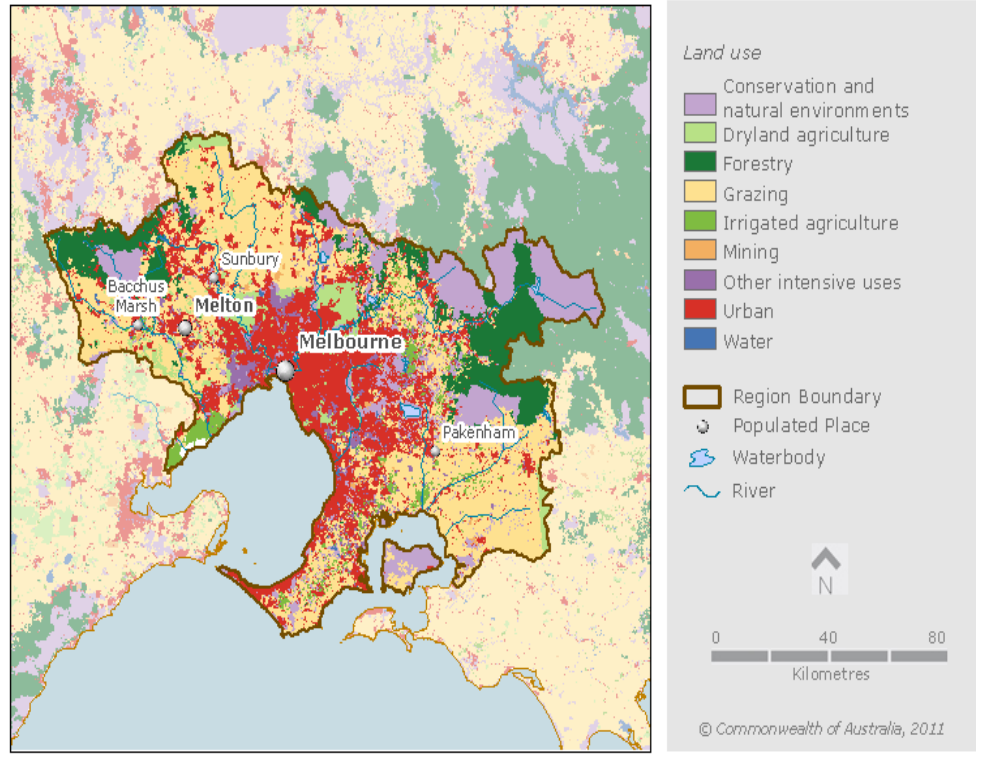

Figure 1- Land Use in Melbourne (Source: Bureau of Meteorology, Australia)

States like Victoria in Australia are currently facing the consequences of its high urban growth rate which drives the attention of promoting greener space within the region. Western Melbourne region is one of the areas in Australia that has a high urban growth rate which concentrates $16.2 \%$ of total population of metropolitan Melbourne and 12\% of Victoria's population. The number of citizens in this area is expected to reach 850,000 by 2030 . Some of the adverse effects include the likelihood of experiencing increased bushfire risk due to higher temperatures and drier conditions. As an example, Bendigo the number of days experiencing high or extreme fire weather is predicted to increase from 18 days to 30 days annually by 2050 . The number of temperature-related deaths is projected to be up to 1164 in the year 2100 within Victoria. 
Jayasooriya and Ng, Development of a framework for the valuation of Eco-System Services of Green Infrastructure

According to the land use map of Melbourne (Figure 1), less green space is available within Melbourne due to urbanization. The cities need to provide more green space to balance out the problems caused by urban sprawl in order to maintain the a livable city. Therefore, it is important to have a comprehensive study on the value of GI, and to get an idea on the ESS they provide for appreciation and more investment of GI. This research is an attempt to develop a framework that can guide the stakeholders to quantify the multiple benefits of GI in terms of ESS that they can provide.

\section{AIM OF THE PROJECT}

The aim of this project is to develop a framework that has the capability to give a holistic assessment on ESS of GI practices which enables a wider community to appreciate the greater benefits of various GI within their community. The framework will provide guidance to stakeholders in determining ESS in monetary values. The developed framework will then be applied using a hypothetical case study in Melbourne Australia.

\section{DEVELOPMENT OF FRAMEWORK}

The resource units of each ESS are identified and allocated by considering the direct and indirect benefits that the GI can provide for the valuation. By applying the simple mathematical formulas evaluation is done per annual basis by applying the site specific conditions of the study area. The final benefit is then converted to a common unit as the dollar value to obtain the cumulative tangible benefit.

As stated earlier, GI practices are grouped into structural and non-structural measures. The scope of this project is only limited to structural GI practices. In this project, ESS has been categories into six main groups and has been used to map onto the benefits of various GI practices. These groups are water, energy, air, urban heat island, climate change and community livability. An overview of the framework is shown in Figure 2.

The GI practices that provide each and every ESS is identified and categorized in order to derive the simple equations in quantification of those benefits. The calculations in quantifying the ESS are adopted from previous literature. The scope of this project is limited to develop a generic framework of GI practices and its benefits. Further research is required to develop a general idea on the value of the benefit for the appreciation of GI practices rather than producing precise comprehensive numerical values. For more accurate results complex modeling methods should be applied. Wide range of different GI practices that involves different mechanisms is available in the literature and the practices that provide the selected ESS were identified by refereeing previous literature. The equations and methods for the quantification were also identified from previous researches which are applied for the valuation. The framework has been developed by adopting and modifying the report for "value of green infrastructure by Center for Neighborhood Technology" (CNT, 2009). In the following sections, methods to quantify each ESS will be discussed.

\subsection{Water}

The benefits of GI for water can be obtained in two ways as volume of runoff reduction or volume of water captured for reuse. The volume captured for reuse can produce economic benefit in terms of reducing the water bills. The volume of runoff reduction can also produce economic benefits in the contexts where stormwater is directed to a treatment plant by reducing the treatment costs. To identify the water benefit, it is important to evaluate the rainfall- runoff that is generated from the site. For this, different methods such as Soil Conservation Service (SCS) curve number method, rational methods or hydrographs (Poullain 2012) can be applied. For the volume of runoff reduced by infiltration practices Green-Ampt method (Heasom et al., 2006) is applied. Finally, to get the cumulative benefit is obtained by getting the monetary values of avoided treatment costs due to runoff reduction and the value of water captured for reuse. Water quality, water demand, hydrology, price of a water unit, soil type and the rainfall of the interest area are needed for a comprehensive evaluation process.

\section{Total runoff reduction= Annual Precipitation * GI Feature Area * Percentage retained}

\subsection{Energy}

GI practices such as green roofs, green walls and trees can contribute to energy savings in two different ways. It can reduce the building energy use by cooling the surroundings in hot weather conditions. And also they can reduce the energy use in water treatment plants by reduction of the runoff volume that enters to the plant. Data on heating and cooling degree days are used in energy balance calculations to produce the amount of 
Jayasooriya and Ng, Development of a framework for the valuation of Eco-System Services of Green Infrastructure

energy reduction in heating for cold weather conditions and cooling for warm weather. The resource unit used is Kwh if the energy source is electricity or Btu if natural gas. The dollar value of the energy benefit is obtained by comparing the reduced energy units with the energy prices of the specific area.

\section{Annual number of cooling/heating savings = Annual number of cooling/heating degree days* 24 hrs/day *} difference between heat transfer coefficients of conventional and green practice

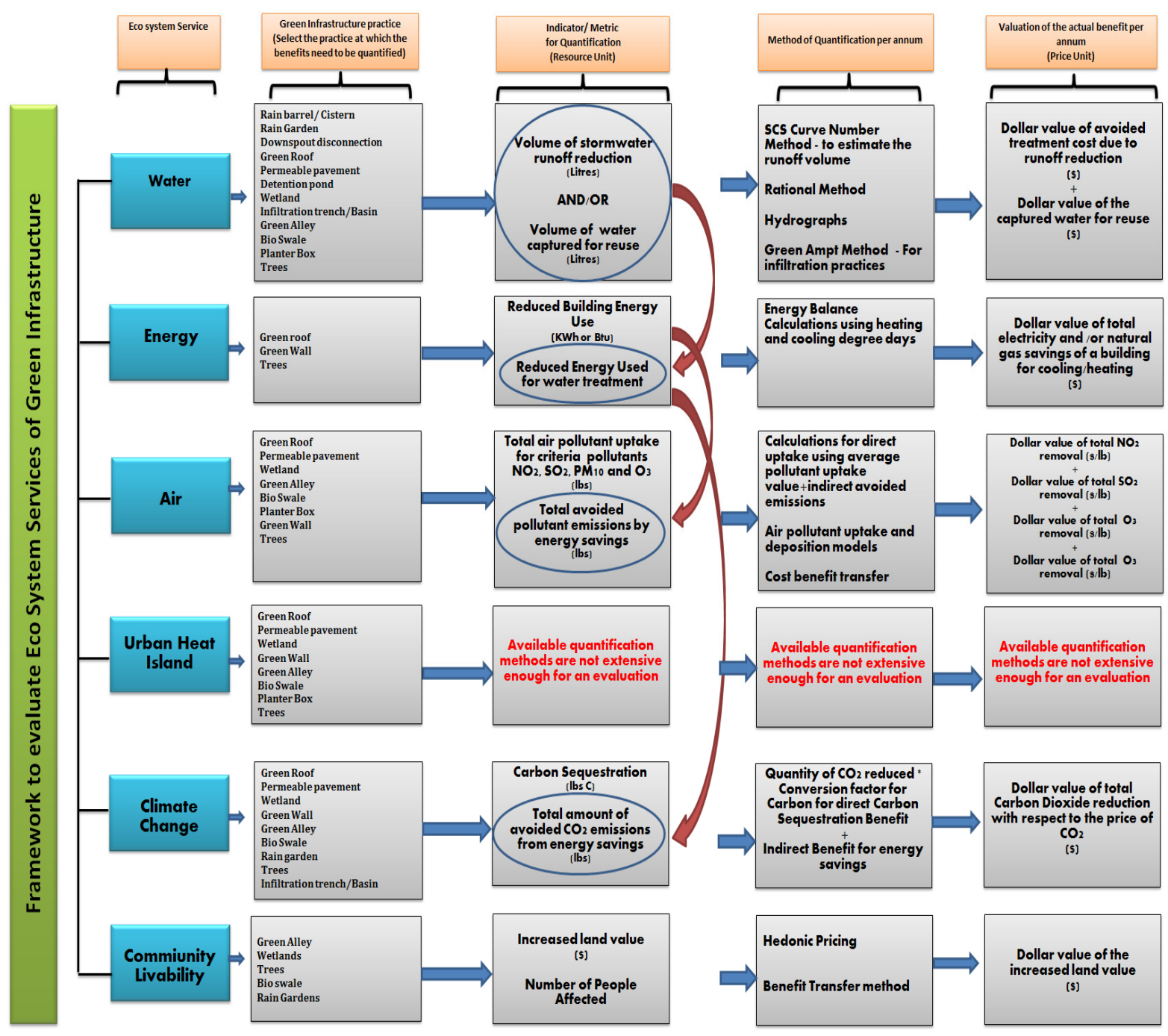

Figure 2- Framework to evaluate the ESS of GI

\subsection{Air}

Green roofs in particular have reported in the literature that it can uptake criteria air pollutants like Nitrogen Dioxide, Sulfur Dioxide and Ozone through leaf stomata and intercept particulate matter (Wise et al., 2010). Some of the other practices that contribute to air quality benefits include trees and bio-retention. A study in Chicago has found that the green roofs can contribute to remove 52 percent of $\mathrm{O}_{3}, 27$ percent of $\mathrm{NO}_{2}, 14$ percent of PM10 and 7 percent of $\mathrm{SO}_{2}$ from the atmosphere (Yang et al., 2008). Apart from the uptake of criteria pollutants the indirect benefit of air quality can be provided by the reduction of emissions of the energy savings in section 4.2. The cumulative air quality benefit is converted to its monetary value by substituting the amount of air pollutant uptake for their dollar values in the area.

\section{Pollution Flux = Deposition Velocity * Concentration of Air Pollution}

$F_{i}=V d_{i} * C_{i} \quad i=$ Type of the air pollutant $\left(\mathrm{NO}_{2}, \mathrm{SO}_{2}, \mathrm{O}_{3}, \mathrm{PM} 10\right)$ 
Jayasooriya and Ng, Development of a framework for the valuation of Eco-System Services of Green Infrastructure

Total flux to the green cover by air pollutant $(i)=F_{i t}$

$F_{i t}=F_{i} * A$ (Green Cover) $* T$ (Time)

The total amount of air pollutants removed by the green cover $(F)=\sum F_{i t}$

\subsection{Urban Heat Island (UHI)}

UHI is a phenomenon where urban temperatures are significantly higher than those of its surrounding areas in summer time. (Xu et al., 2012). Almost of all the GI practices have the ability of reducing UHI by evaporative cooling, reducing building energy consumption or reducing ground conductivity. Thus the valuation of UHI is difficult due to its complex nature (Wise et al., 2010). Very few research studies are currently completed in quantifying for UHI and no sufficient valuation methods are found to conduct an assessment on the UHI benefit of GI. (CNT, 2009)

\subsection{Climate Change}

According to the climate predictions in urban areas across the world, it will experience more extreme precipitation and temperature, increased storm frequency and intensity and sea level rise within next few years (Foster et al., 2011). GI practices provide ESS to the climate change directly and indirectly. The amount of Carbon Dioxide emissions that is reduced from the GI is used as the resource unit to quantify the climate change benefit. The direct benefit from Carbon sequestrated and the indirect benefit from reduced Carbon Dioxide emissions from energy savings is calculated to obtain a cumulative climate change benefit. To get the monetary benefit of climate change and adaptation the total amount of reduced Carbon Dioxide emissions is multiplied by the Carbon Dioxide price of the specific region.

$$
\begin{aligned}
& \text { Annual amount of Carbon Sequestrated = Total Area of Practice *Average annual amount of Carbon } \\
& \text { sequestered }
\end{aligned}
$$

\subsection{Community Livability}

GI practices can improve community livability by improving aesthetics, creating recreational opportunities, reducing noise pollution and creating community cohesion. (CNT, 2009). Though it is hard to develop a resource unit for the direct benefit from community livability, previous studies have proven that practices that improve green cover like trees, wetlands and green alleys can increase the land value of a certain area. Therefore in developing the framework, increased land value is taken as the indicator or performance metric and the valuation methods include hedonic pricing and cost benefit transfer which are most commonly used in the economic valuation of ESS. Hedonic regression analysis would be a more appropriate method to evaluate the property value increase by a green practice. It can analyze the relationship between price of the property as dependent variable and the changes of value due to the surrounding greenery areas as the depending variable. An example hedonic function for a price of a property can be explained as follows.

$$
\text { Price }=f(l o c a t i o n, \text { neighborhood, view, green space, size) }
$$

\section{APPLICATION OF DEVELOPED FRAMEWORK USING A HYPOTHETICAL CASE STUDY}

The developed framework considering the six ESS's is shown in Figure 2. An example using the framework to determine the benefits of applying green roof in Melbourne has been demonstrated. Since West of Melbourne is a growing region and it has many GI application potential to increase the livability within the community. The following typical West of Melbourne climatic conditions have been adopted for this example. The aim of this example is to demonstrate the benefits of applying green roof in an urban setting.

Table 1 - Climate Conditions of Melbourne

\begin{tabular}{lll}
\hline Annual Rainfall & $650 \mathrm{~mm}$ & Source : bureau of meteorology \\
\hline Annual heating degree days & $1809\left({ }^{\circ} \mathrm{C}\right.$ Days $)$ & Source $:$ http://www.degreedays.net/ \\
Annual Cooling Degree Days & $371\left({ }^{\circ} \mathrm{C}\right.$ Days $)$ & Source $:$ http://www.degreedays.net/ \\
\hline
\end{tabular}

\subsection{Valuation for the Green roof}

Green roof provides water, energy, UHI, air quality and climate change benefits. To calculate the water benefit is it is important to know the percentage of runoff retained in the GI practice. Empirical studies of green roofs have found that, in any location green roofs can retain $40 \%-80 \%$ of annual precipitation. (CNT, 2009) By using an average of $60 \%$ retaining rate, a hypothetical green roof area of 300 square meters in a 
Jayasooriya and $\mathrm{Ng}$, Development of a framework for the valuation of Eco-System Services of Green Infrastructure

typical suburban West of Melbourne, it can reduce 93 kiloliters of runoff per year. If this water is captured, then it means a saving of 93 kiloliters of potable water.

In Melbourne the stormwater is directly discharged to the natural water ways and therefore in energy calculations only reduced building energy use of applicable. In calculating the reduction of building energy use annual heating and cooling degree days for Melbourne (Table 1) are used and it has been is shown that for the same area of green roof, it can achieve savings of $3765 \mathrm{Kwh}$ per annum. By using the residential energy charges per unit explained by energy Australia, this can provide an economic benefit of \$1086AUD per year.

Table 2 - Data for annual criteria pollutant update by green roofs (Source: McPherson et al 2006, Currie and Bass, 2008 and Yang, Qian and Gong, 2008))

\begin{tabular}{llll}
\hline Criteria Pollutant & High $\left(\mathbf{K g} / \mathbf{m}^{2}\right)$ & Low $\left(\mathbf{K g} / \mathbf{m}^{2}\right)$ & Price (AUD/Kg) \\
\hline $\mathbf{N O}_{2}$ & 0.002329 & 0.001464 & 7.65 \\
$\mathbf{O}_{3}$ & 0.004491 & 0.002870 & 7.65 \\
$\mathbf{S O}_{2}$ & 0.001982 & 0.001117 & 4.72 \\
PM10 & 0.000649 & 0.000556 & 6.50 \\
\hline
\end{tabular}

Table 3- Emissions Factors of electricity for pollutants (Source: CNT 2009)

\begin{tabular}{lr}
\hline $\mathrm{NO}_{2}(\mathrm{Kg} / \mathrm{kWh})$ & 0.0008786 \\
$\mathrm{SO}_{2}(\mathrm{Kg} / \mathrm{kWh})$ & 0.002385 \\
\hline
\end{tabular}

The valuation of the direct benefit of the air quality improvement by green roof is done by selecting the four criteria pollutants $\mathrm{NO}_{2}, \mathrm{O}_{3}, \mathrm{SO}_{2}$ and PM10. Data obtained by the literature for pollutant uptake by green roofs and the prices of each pollutant as shown in Table 2 are used for the calculation. The valuation of indirect benefit of energy savings is also calculated by using the energy factors described in US EPA 2005. (Table 3) The results have indicated that 300 square meter of green roof in Melbourne can reduce total amount of NO2 annually by $4.5 \mathrm{Kg}, \mathrm{O}_{3}$ by $1 \mathrm{Kg}$., $\mathrm{SO}_{2}$ by $3 \mathrm{Kg}$ and $\mathrm{PM} 10$ by $0.2 \mathrm{Kg}$. This leads to a total air quality benefit of \$59AUD per year.

Table 4- Average emissions intensity of electricity generation (Australia 2010), Source: Productivity Commission estimates.

\begin{tabular}{ll}
\hline Fuel & $\begin{array}{l}\text { Emissions Intensity }(\mathbf{K g} \\
\left.\mathbf{C O}_{2} / \mathbf{K w h}\right)\end{array}$ \\
\hline Brown Coal & 1.200 \\
Oil & 0.970 \\
Black Coal & 0.920 \\
Gas & 0.540 \\
Renewables & 0 \\
Australian Coal Average & 1.000 \\
Australian Fossil Fuel Average & 1.002 \\
\hline
\end{tabular}

For the valuation of climate change benefit, amount of carbon sequestrated and the reduced carbon dioxide emissions from energy savings should be taken into account. Due to the lack of data to calculate carbon sequestration benefit, only the indirect savings are calculated within in this section.

Since green roof can reduce energy savings by $3765 \mathrm{Kwh}$ per year the amount of $\mathrm{CO}_{2}$ emissions per that particular amount should be calculated. Average emissions intensity of $\mathrm{CO}_{2}$ from electricity generation is presented in Table 4. As the primary source of producing energy at state of Victoria is brown coal, the emissions intensity $1.2\left(\mathrm{Kg} \mathrm{CO}_{2} / \mathrm{Kwh}\right)$ is selected for the calculation. The result shows that $4516 \mathrm{Kg} \mathrm{of} \mathrm{CO}_{2}$ is annually reduced by 300 square meter green roof area. According to the Carbon prices explained by clean energy regulator Carbon pricing mechanism, Carbon Price for Australia in 2013-2014 will be \$0.024 per Kilogram. Therefore the total dollar value of the climate change reduction by a green roof can be evaluated as $100 \mathrm{AUD}$ for a year.

\section{DISCUSSION AND CONCLUSIONS}

The valuation of ESS is important in decision making of investment for the long term implementation of GI practices. Though this area has created an interest among general public and water resource professionals as a stormwater management strategy, valuation of the additional benefits it creates will provide more enthusiasm for people to appreciate the value of GI and do more investments on them. Yet, for a precise valuation a large 
Jayasooriya and Ng, Development of a framework for the valuation of Eco-System Services of Green Infrastructure

amount of data is needed and new methodologies should be developed for measuring the benefit of ESS like UHI. This project is only limited for developing the initial framework for the valuation process and giving the exact numbers for the benefits is beyond the scope of this research.

In this paper, a framework has been developed and using green roof as an example to demonstrate the application of the framework. Valuation is conducted for a green roof area of 300 square meter located in the west of Melbourne and the results shows it can provide an environmental benefit of reducing the annual rainfall runoff by 93 kiloliters. The total energy, air quality and climate change benefit can be approximately $\$ 1245$ AUD per year. For the calculation of the social benefit of the improvement of community livability some extensive amount of data is needed within a considerable time. At the same time a calculation of UHI benefit is not conducted due to the lack of data. Therefore, the presented benefit is under estimated and the dollar value of the cumulative benefit for a green roof can be a higher quantitative value than it is presented here. To have an idea of actual feasibility of GI, a cost benefit analysis should be conducted by considering the life cycle costs for implementation, operation and maintaince for certain practices. However, the results of this study emphasizes that it is valuable in investing for GI within communities not only for its benefits on stormwater management, but also in creating a sustainable environment.

\section{REFERENCES}

ASLA. (2003). Chicago City Hall Green Roof. Retrieved 12 May, 2013, from http://www.asla.org/

Center for Neighbourhood Technology. (2009). The Value of Green Infrastructure. A Guide to Recognizing its Economic, Environmental and Social Benefits.

Clean Energy Regulator. (2013). Carbon Pricing Mechanism. Retrieved 19 May, 2013, from http://www.cleanenergyregulator.gov.au/Carbon-Pricing-Mechanism/Pages/default.aspx

Currie, B., \& Bass, B. (2008). Estimates of air pollution mitigation with green plants and green roofs using the UFORE model. Urban Ecosystems(11), 409-422.

Degree Days. Weather data for energy professionals. Retrieved 01 June, 2013, from http://www.degreedays.net/

Eliot, A., H, \& Trowsdale, S., A. (2006). A review of models for low impact urban stormwater drainage. Environmental Modeling and Software, 22, 394-405.

Foster , J., Lowe, A., \& Winkelman, S. (2011). The value of Green Infrastructure for urban climate change adoptation. http://www.cakex.org/sites/default/files/Green_Infrastructure_FINAL.pdf

Green Infrastructure. City of Sydney. Retrieved 10 May, 2013, from http://greeninfrastructure.net.au/

Heasom, W., Traver, R. G., \& Welker, A. (2006). Hydrologic Modeling Of A Bio infiltration Best Management Practice1. JAWRA Journal of the American Water Resources Association, 42(5), 1329-1347.

Hobsans Bay City Council. Greening the West. Retrieved 2 May, 2012, from http://www.hobsonsbay.vic.gov.au/Environment_and_waste/Greening_the_West

MacMullan, E., \& Reich, S. (2007). The economics of low-impact development: A literature review. ECONorthwest, Eugene, OR.

Mcmahon, E., T, \& Benedict, M., A. (2006). Green Infrastructure Linking landscapes and communities. The conservation fund: Island Press.

McPherson, E. (2006). Midwest community Tree guide: Benefits, costs, and strategic planting. US Department of Agriculture, Forest Service, Pacific Southwest Research Station.

Melbourne Physical Information. (2011). Retrieved 31 May, 2013, from http://www.bom.gov.au/water/nwa/2010/melbourne/context/physical

Poullain, J. (2012). Estimating Stormwater Runoff. Florida Erosion and Sediment Control Inspector's Manual.

Productivity Commission. Australia's Electricity Generation Sector Retrieved 02 June, 2013, from http://www.pc.gov.au/_data/assets/pdf_file/0004/109921/13-carbon-prices-appendixd.pdf

Tzoulas, K., Korpela, K., Venn, S., Yli-Pelkonen, Kaźmierczak, A., Niemela, J., \& James, P. (2010). Promoting ecosystem and human health in urban areas using green infrastructure: a literature review. Landscape and urban planning, 81(3), 167-178.

Victoria Climate change impacts in Vic. Retrieved 24 May, 2013, from http://www.climatechange.gov.au/climatechange/climate-science/climate-change-impacts/victoria

Wise, S., Barden, J., Ghalayini, D., Grant, J., Kloss, C., Macmullan, E., . . Yu, C. (2010). Integrating Valuation Methods to Recognize Green Infrastructure's Multiple Benefits. Low Impact Development, 1123-1143.

Yang, J., Yu, Q., \& Gong, P. (2008). Quantifying air pollution removal by green roofs in Chicago. Atmospheric Environment, 42, 7266-7273. 